Роль этносольфеджио в сохранении

\section{и развитии песенного наследия казахов} в условиях глобализации

\section{Байбек А.К.}

Казахский национальный университет искусств,

Нур-Султан, Республика Казахстан.

(iD https://orcid.org/0000-0002-3495-1926, e-mail: aigul.akzhelen@gmail.com
DOI 10.31483/r-64072

УДК 781.7(574)

Резюме: Статья посвящена проблеме сохранения и передаче традиционной музыки казахов в эпоху глобализации. Цель статьи - раскрыть содержание образовательной программы «Традиционное музыкальное искусство» и выявить роль этносольфеджио в профессиональной подготовке студентов. На основе методов обобщения педагогического опыта (наблюдения, изучения нормативной документации, анкетирования) представлен многолетний опыт преподавания курса этносольфеджио, адаптированного для народных певцов. В результате проведенной работы была получена необходимая теоретическая и практическая база для осмысления исторического развития традиционной музыки, понимания её роли в современных культурных контекстах и необходимости её сохранения и дальнейшего развития. В статье делается вывод о том, что новизна курса этносольфеджио состоит в разработке творческих форм работы, опирающихся на свойственную традиционным певцам устность и импровизационность, ведущих к раскрытию композиторского потенциала, что является залогом сохранения ценностных качеств традиционной музыки, обеспечивая её дальнейшее развитие.

Ключевые слова: традиционная музыка, этносольфеджио, устное восприятие, искусство импровизации, творческие формы работы.

Для цитирования: Байбек А.К. Роль этносольфеджио в сохранении и развитии песенного наследия казахов в условиях глобализации // Этническая культура. - 2019. - № 1 (1). - C. 19-23. DOI:10.31483/r-64072.

\title{
The Role of Ethnosolfeggio in the Preservation and Development of Kazakhs' Song Heritage in the Conditions of Globalization
}

\author{
Aigul K. Baibek \\ Kazakh National University of Arts, \\ Nur-Sultan, Republic of Kazakhstan. \\ https://orcid.org/0000-0002-3495-1926, e-mail: aigul.akzhelen@gmail.com
}

\begin{abstract}
The article is devoted to the problem of preserving the spirit and creative potential of the traditional music in the modern Europeanized education of folk musicians in Kazakhstan. In the modern ethnosolfeggio course, adapted for folk singers, the necessary basis is formed for understanding the historical development of traditional music and its role in modern cultural contexts, as well as the need for its preservation and further development. The purpose of the article is to offer the measures to preserve the valuable qualities of traditional music and ensure its further development. Based on the methods of generalizing pedagogical experience (observation, studying normative documentation, questionnaires), many years of experience in teaching a course of ethnosolfeggio adapted for folk singers are presented. As a result of the work, the necessary theoretical and practical basis was obtained for understanding the historical development of traditional music, understanding its role in modern cultural contexts and the need for its preservation and further development. The article concludes that ethnosolfeggio course include saturation with creative forms of work that rely on "verbalness» inherent to traditional singers, and emphasis on mastering improvisation that unfolds the composing potential.
\end{abstract}

Keywords: traditional music, ethnosolfeggio, oral perception, art of improvisation, creative forms of work.

For citation: Baibek A.K. (2019). The Role of Ethnosolfeggio in the Preservation and Development of Kazakhs' Song Heritage in the Conditions of Globalization. Etnicheskaya kultura = Ethnic Culture, 1(1), 19-23. (In Russ.) DOI:10.31483/r-64072.

\section{Введение}

Казахстане в результате тотальной европеизации образования музыкантов в настоящее время доминирующей формой публичного исполнения исконно сольных традиционных кюев стало оркестровое, а песен - в «обработках» под оркестр, фортепиано или баян. Классические произведения прошлого звучат в «современной оправе». Музыканты-народники стали заложниками системы образования, созданной в 40-е годы XX века и ориентированной на европейскую. Несмотря на неадекватное традиционной музыке обучение, нивелирующее импровизационность, композиторское начало и особенности исполнительства различных локальных школ, среди выпускников учебных заведений немало исполнителей-профессионалов с мастерским владением техни- кой, широчайшим репертуаром, яркой интерпретацией произведений прошлого. Однако, среди них очень мало создателей новых произведений (кюи, песни). А их творческая активность несравнима с деятелями прошлого.

Memodbl обобщения педагогического опыта позволили нам обосновать условия внедрения творческих форм работы в практику подготовки студентов. Сегодня необходимо через трансляцию духовных ценностей традиционной музыки в современном учебном процессе способствовать формированию не только творчески активных исполнителей, но и создателей новых произведений. В результате анализа профессиональной подготовки студентов, было выявлено, что подготовка будущего музыканта принципиально не ориентирована на воспитание носителей и продолжателей опре- 
деленной автохтонной аутентичной исполнительской традиции. Мы осознаем, что сегодня для сохранения наследия, как никогда актуально возрождение духа традиционного аутентичного исполнительства. Важно воспитать у современных музыкантов отношение к аутентичному исполнительству, как воплощению в своих интерпретациях почерка самых выдающихся и оригинальных композиторов-исполнителей классической традиции. Мы не должны забывать, что именно аутентичное исполнение - это основа наиболее полного и точного воспроизведения авторского замысла, художественного образа исполняемой музыки. Сохранение музыкального наследия в его аутентичном виде - есть сохранение неповторимого содержания музыки прошлых эпох, мироощущения и чувствования ушедших поколений, это сохранение духовного мира, в котором они жили. И главное - это сохранение основы, без которой невозможна преемственность и дальнейшее развитие традиционного музыкального искусства народа.

Обсуждение. Как известно, в процессе исторического формирования традиционной музыки ее непрерывное развитие осуществлялось талантливыми личностями - представителями различных устно-профессиональных песенных школ Казахстана. Жизнь устной культуры невозможна без передачи опыта и знаний непосредственно при жизни этих выдающихся музыкантов, созидающих новое и тем самым развивающих традицию. Этому служила отработанная веками система устного обучения музыкантов Ұстаз-шәкірт (Учитель-ученик).

Глобальные социальные изменения первой половины XX века привнесли в Казахстан традиции европейской музыкальной культуры с её системой обучения, которая сложилась в опоре на нотную письменность. В консерватории невозможно возродить традицию Ұстаз-шәкірт в силу множества объективных и субъективных причин. Эти функции развития песенной традиции отчасти взяло на себя «современное казахское любительское музицирование - единственная в музыкальной практике послереволюционного Казахстана форма музыкальной деятельности, развивающаяся на основе устной песенной традиции» [1, с. 57]. Корневым для любительского типа творчества явилось возникновение нового жанра - «массовая песня», рассчитанного на массовое исполнение, которое больше других соответствовало идеологической направленности. Постепенно, как следствие изменений формы бытования произошло вытеснение термина «массовая песня» термином «советская песня», затем появляется новое сочетание - «эстрадная песня». Для всех этих новых песенных жанров как советского и пост советского периода традиционная песня служила основой развития. И в то же время сама традиционная песня как фольклорная, так и профессиональная - в её аутентичном виде была оставлена «на задворках культуры». Ей была определена роль культурного реликта, который постепенно терял актуальность и как следствие массовую слушательскую среду.

Мы вынуждены констатировать, что последние десятилетия существует активная тенденция - приток в поп-музыку профессиональных народных певцов, обучившихся в системе высшего музыкального образования, которая служит для подготовки носителей традиционной культуры. Некоторые народные певцы, втягиваясь в «попсу», приходят со своим традиционным репертуаром. Таким образом, традиционные вокальные жанры служат «сырьем» для аранжируемых композиций: начиная от фольклорных и классических авторских лирических песен до малых эпических жанров. В результате тотального распространения этого на сегодня модного течения сложился «новый» исполнительский стиль. В большинстве случаях в подобных исполнениях не учитываются музыкальная семантика выбранного для китча «оригинала», полностью искажается глубинный смысл сочинения. Как правило, такое искусственно созданное стилизованное исполнительство, сформированное сугубо для развлечения, не обладает глубоким эстетическим и энергетическим воздействием. Губительным последствием чего явилось - потеря культуры восприятия, большая часть современных слушателей, независимо от возрастных категорий, - это заложники подобных «сочинений-однодневок». Многие из современников даже и не подозревают, что традиционная музыка служила не только средством развлечения и наслаждения, она была способом гармонизации бытия, единения человека и космоса, она воплощала «принцип универсальной всеобщности» [2, с. 79]. Традиционная музыка благоприятно влияла на духовное состояние общества, каждый человек, внимая музыке, приобщался к высшим сферам духовности.

Сегодня время как никогда настойчиво требует Исполнителя с большой буквы, продолжателя классических традиций традиционного пения. Неся базовые эстетические и морально-этические ценности традиционной музыкальной культуры, а также пользуясь возможностями, привнесёнными знанием нот и классической европейской музыки, такой исполнитель смог бы адаптироваться в различных видах и формах деятельности современной культуры, в которой на глобальном уровне идёт активное взаимодействие различных музыкально-стилевых систем.

Полное осмысление современными народными исполнителями не только индивидуального исполнительства, но и своей последующей профессиональной деятельности может быть осуществлено на основе знаний, закладываемых в системе высшего музыкального образования. Однако, поскольку сами закономерности музыкального искусства исторически формируются, развиваются, трансформируются, постольку и разработанные музыкально-теоретические основы должны строиться в соответствии с процессом исторического движения музыкального творчества. А для этого необходимо понимание перспектив развития традиционной музыки. Важнейшим предметом, формирующим глубинное понимание закономерностей музыки в системе обучения музыкантов, является сольфеджио. Долгое время прохождение этого курса было основано на музыке Европы. На рубеже веков на территории бывшего СССР активизировался процесс создания, официаль- 
ного признания и внедрения в учебный процесс курсов сольфеджио, которые основываются на музыке национальных культур. Их называют этносольфеджио [3-5].

Этносольфеджио в Казахстане создало благоприятные условия для воспитания исполнителей нового поколения. Многолетняя практика этносольфеджио показывает, что изложение теоретических основ казахской традиционной музыки, закрепляемое в практической деятельности, дает возможность глубже вникать в суть музыки, раскрывает творческий потенциал студентов, импровизаторские и даже композиторские способности.

Песенная традиция XIX века (классический период) представляет собой одно из наиболее ярких, знаковых явлений казахской традиционной музыки. В этой связи, подлинное раскрытие ценностных качеств самой культуры немыслимо без знаний стилистических особенностей различных исполнительских школ и композиторских индивидуальностей. Изучение устно-профессионального песенного стиля предполагает поэтапные исследования по восстановлению целостной картины его формирования и развития. В этой связи, необходимо сквозное изучение стилевых особенностей - музыкального языка и формообразования как фольклорных, так и устно-профессиональных песен, что позволяет выстроить иерархическую систему усложнения песенных форм, необходимых для последовательного теоретического и практического освоения песенного стиля в курсе этносольфеджио. Исследуемый в курсе песенный стиль различных исполнительских школ (Ахан сери, Биржан сал, Асет, Мухит, Кенен и др.), как стиль определенной школы в лице неповторимых индивидуальностей, а также конкретно стиль одного произведения отдельного автора представляет в целом традиционный стиль целой исторической эпохи.

Традиционный песенный стиль, связывая всю многоликость рассматриваемых явлений, представляет объективное художественное единство, пронизывающее все стороны традиционной песни - функционально-жанровой, образно-поэтической характеристики, музыкального языка и формообразования. При этом важнейшим компонентом, безусловно, является композиторский замысел (в лице выдающихся певцов-классиков), так как именно «в творческом замысле концентрируются все элементы музыкального искусства, - в нем, в свете эстетических тенденций композитора, художественно отображается действительность, он формируется под воздействием национальных традиций художественной культуры, школы, в нем находят живой отклик запросы исполнительской практики своего времени и интересы слушательской аудитории» [6, с. 11].

Таким образом, учебный курс этносольфеджио для народных певцов преследует цель - выстроить систему знаний, которая стала бы основой теоретического и практического усвоения песенного стиля, созданного выдающимися творцами.

Теоретическое изучение песенного стиля конкретных творцов представляет комплекс музыковедческих, филологических и культурологических знаний. Это изучение мировоззрения автора, особенностей поэтики и ритмики стиха, жанровых функций, а также му- зыкально-стилевых основ его песен. Стилистический анализ песенного наследия всех композиторов-певцов классического периода построен на едином дидактическом принципе. Это анализ следующих компонентов: мировоззрение певца (тотально религиозное у музыкантов прошлого), знаковые события биографии, обучение (медресе и Ұстаз-шәкірт), творческий портрет, тематика, содержание и поэтическая основы песен, а также индивидуально-стилевые и формообразующие особенности песенного наследия. Данная формы работы направлена на формирование не только музыкального мышления, но и на формирование студентов как будущих исполнителей, носителей ценностных установок культурной традиции.

Связанные непосредственно с европейским сольфеджио письменные формы работы занимают большое место в курсе этносольфеджио, в основные задачи которых входят: свободное овладение нотным письмом и навыками расшифровки, а также привитие студентам навыков транспозиции песен в строй домбры и реконструирование ранее изданных песен, так как основная часть нотировок казахских песен дана без учета домбрового строя, а мелодии записывались в абсолютной высоте звучания. Многие нотированные песни из-за неточностей записи никогда не исполнялись, поэтому одной из главных задач курса этносольфеджио является редактирование таких песен и транспонирование их в домбровый строй. Реконструирование же ранее изданных песен предназначено для активного привлечения народных певцов к дальнейшей работе с этнографическими сборниками, необходимыми в их будущей исполнительской деятельности - возрождению и пропаганде богатейшего собрания песен казахского народа в записях А. Затаевича («1000 песен казахского народа» и «500 казахских песен и кюев»), введению в концертную жизнь «новых песен» устно-профессиональной традиции, неисполняемых, несохраненных в аудиозаписях, и неполно зафиксированных в нотах.

Все же одной из приоритетных задач курса этносольфеджио является формирование навыков устного восприятия песен как продукта синкретического творчества. Достаточно сказать, что сегодня традиционная песня в новой концертной интерпретации лишилась неотъемлемой в традиционных условиях исполнения повествовательной части, рассказа, который непосредственно предварял акт музицирования и нес важное для понимания сути исполняемого сочинения художественное значение. Поэтому одной из форм работы стало изучение историй создания песен и отработка навыков их (историй) художественно-артистического воспроизведения перед исполнением песни.

Отсюда вытекает важный методологический принцип - в курсе этносольфеджио для традиционных певцов изучение музыкальных закономерностей должно идти в единстве с изучением закономерностей строения стиха. Ведь стих определяет образно-эмоциональную сторону песни, структуру её мелодики. Поэтому важно не просто изучение стиховых структур, но и стихотворной поэтики. Современные реалии таковы, что не только в науке произошло разделение неделимого 
по своей сути жанра «песни», которая являет синтез вербального и музыкального начал: музыковеды изучают её музыкальные закономерности, филологи - поэтические. В курсе этносольфеджио необходимо не только сохранить с детства интуитивно постигнутое цельное восприятие песни, но и углублять это интуитивное знание, выработать у студентов понимание значения каждого слова, его глубинного образного смысла. Эта работа приведёт к знанию целостного музыкально-поэтического языка песни. В свою очередь, это станет основой более глубокого понимания песни и, следовательно, более глубокой и творческой её исполнительской трактовке.

В современных условиях обучения студентов-народников особенно актуальным становятся вопросы сохранения и развития тех ценностных качеств традиционной музыки, которые связаны с её исконно устной природой. Адаптация традиционных методов воспитания народных музыкантов в европеизированной системе обучения включает в себя традиционные методы обучения и воспитания устного профессионала. Ими являются: устность, импровизационность, всевозможные творческие виды работ, а также включение традиционных форм песенного общения. В числе устных форм работы, связанных с привычной системой восприятия традиционных песен, мы выделили - устный музыкальный диктант на основе устно-профессиональных песен, так как именно устная фиксация, кровно связанная с вековой традицией устного музицирования, отражает традиционный метод усовершенствования слуха и памяти. Эта форма работы, сопровождаемая стилистическим анализом, дает возможность пополнения традиционного репертуара, прививает студентам умение давать эстетическую оценку услышанной песни.

Введение в этносольфеджио системы творческих форм работы обусловлено рядом приоритетных задач, поставленных перед системой образования в целом. Это - воспитание креативной личности, раскрепощение и развитие творческого потенциала учащегося для эффективной общественно-профессиональной деятельности музыканта в самых различных сферах.

В целом, различные формы работы над импровизацией-сочинением в стиле выдающихся представителей различных исполнительских школ направлены в первую очередь на глубинное осмысление его песен, что позволяет формировать в студентах, прежде всего, понимание индивидуального стиля народных композиторов-классиков и умение в целом давать эстетическую оценку ценности традиционных песен. Создание же индивидуальных «оригинальных» музыкальных сочинений, ориентированных на лучшие композиционные шедевры, может быть реализовано только при изучении стилевых особенностей песенного наследия различных исполнительских школ. Выполненные в учебном курсе импровизации-сочинения студентов на композиционные структуры в целом классических устно-профессиональных песен представляют для нас и для самих студентов большой интерес как первый композиторский опыт. Необходимо поощрять импровизации-сочинения студентов, в которых воплощается опыт традиционного певца как синкретического творца, т.е. когда и текст, и музыка сочиняются самими студентами.

Безусловно, практика данной формы работы дает студентам возможность не просто осознавать, но и реализовывать через свой опыт сочинительства взаимосвязь импровизаторского и исполнительского творчества. В целом, работа над импровизацией и сочинением открывает неограниченные возможности для развития творческих способностей музыкантов, пробуждает в них творческое сознание, заставляет их посмотреть на песню другими глазами и услышать по-новому ту же самую музыку.

Необходимо помнить, что сегодня создание индивидуальных «оригинальных» музыкальных сочинений, ориентированных на лучшие композиционные шедевры классических сочинений, может быть реализовано только в тесном соприкосновении с предшествующим опытом - традицией. Немаловажным является факт современной музыкальной жизни - падение вкусов, снижение эстетических критериев. Нет аналогий традиционным песням, которые исконно выступали «эталоном художественного совершенства» и являлись произведениями высокого профессионального уровня.

Bblвoдbl. Таким образом, в современных условиях необходимо транслировать механизм преемственности композиторского опыта национальных традиций в учебные заведения. Специализированные курсы как этносольфеджио, основанные на освоении жанровой специфики, композиционных закономерностей и средств музыкальной выразительности традиционной песенной, так и инструментальной культуры остро необходимы. Ведь именно в курсе этносольфеджио через практику импровизации и сочинительства предпринимается попытка моделирования деятельности традиционного музыканта-импровизатора, который был не только носителем и продолжателем традиционных исполнительских школ, но также и обладал одновременно универсальными качествами исполнителя-импровизатора и творца. Именно народные певцы, обучающиеся в высших музыкальных учебных заведениях, приобретают все необходимые составляющими для создания импровизаций-сочинений в традиции лучших классических образцов. Они владеют традиционным музыкальном языком, имеют достаточно большой репертуар из традиционных песен, осваиваемых в классе по «Специальности». Дополнив этот комплекс знаниями по курсу этносольфеджио - изучением теоретических основ и практических навыков по традиционной песне - молодые профессионалы без сомнения могут создавать оригинальные и художественно значимые музыкальные произведения - песни в традиционном стиле, которые нашли бы своих слушателей среди современников. 


\section{Список литературы}

1. Абдрахман Г. Современное самодеятельное песнетворчество в казахской музыкальной культуре. - Алматы, 2002. $-176 \mathrm{c}$.

2. Нурланова К. Эстетика художественной культуры казахского народа. - Алма-Ата: Наука, 1987. - 176 с.

3. Аманов Б. Программа курса комплексного сольфеджио для музыкальных вузов / Б. Аманов, А. Мухамбетова, С. Раимбергенова [и др.]. - Алма-Ата, 1991. - 30 с.

4. Альпеисова Г. Теоретические и практические аспекты этносольфеджио в Казахстане: Автореф. дис. ... канд. иск. - А., 2003. - 25 с.

5. Байбек А. Песенный стиль Арки в контексте этносольфеджио (вузовский курс): Автореф. дис. ... канд. искусствоведения. - А., 2009. - 25 с.

6. Скребков С. Художественные принципы музыкальных стилей. - М., 1973. - 446 с.

\section{References}

1. Abdrakhman, G. (2002). Sovremennoe samodeiatel'noe pesnetvorchestvo v kazakhskoi muzykal'noi kul'ture., 176. Almaty.

2. Nurlanova, K. (1987). Estetika khudozhestvennoi kul'tury kazakhskogo naroda., 176. Alma-Ata: Nauka.

3. Amanov, B., Mukhambetova, A., \& Raimbergenova, S. (1991). Programma kursa kompleksnogo sol'fedzhio dlia muzykal'nykh vuzov., 30. Alma-Ata.

4. Al'peisova, G. (2003). Teoreticheskie i prakticheskie aspekty etnosol'fedzhio v Kazakhstane: Avtoref. dis., 25. A.

5. Baibek, A. (2009). Pesennyi stil' Arki v kontekste etnosol'fedzhio (vuzovskii kurs): Avtoref. dis., 25. A.

6. Skrebkov, S. (1973). Khudozhestvennye printsipy muzykal'nykh stilei., 446. M.

\section{Информация об авторе}

Байбек Айгуль Кыдыргаликызы - канд. искусствоведения, доцент кафедры музыковедения и композиции Казахского национального университета искусств, НурСултан, Республика Казахстан.

\section{Information about the author}

Aigul K. Baibek - candidate of art history, associate professor of Music Studies and Musical Work Department at Kazakh National University of Arts, NurSultan, the Republic of Kazakhstan. 